\title{
SELF-IMAGE AND QUALITY OF LIFE OF DERMATOLOGY PATIENTS
}

ADRIANNA POTOCKA ${ }^{1}$, KATARZYNA TURCZYN-JABŁOŃSKA ${ }^{1}$, and MARTA KIEĆ-ŚWIERCZYŃSKA²

${ }^{1}$ Nofer Institute of Occupational Medicine, Łódź, Poland

Department of Work Psychology

${ }^{2}$ Nofer Institute of Occupational Medicine, Łódź, Poland

Out-Patient Clinic of Occupational Diseases

\begin{abstract}
Objectives: The problems of self-image among patients with dermal problems have been seldom explored. As dermal diseases detrimentally affect well-being, functioning and adaptation of dermatology patients, they may decrease the level of self-acceptance. Self-image, on the other hand, may significantly affect the own mental health status and quality of life $(\mathrm{QoL})$ in that group of patients. The aim of our research was to assess mental health status and quality of life of patients with dermal problems in respect of the level of their self-acceptance. Materials and Methods: The participants were patients of the Occupational Diseases Outpatient Clinic and the Occupational and Environmental Allergy Centre of the Nofer Institute of Occupational Medicine (NIOM). In total, 112 patients were examined, including 37 with diagnosed urticaria, 50 with allergic contact dermatitis and 25 with atopic dermatitis. General Health Questionnaire (GHQ) was used to assess patients' mental health, a Polish version of Dermatology Life Quality Index (DLQI) was employed for the assessment of their life quality, while Self-Acceptance Scale (SAS) served to obtain patients' self-image. Results: There were statistically significant differences in the assessment of mental health and quality of life, depending on the level of self-acceptance. People with high self-acceptance are characterised by better mental health condition than those with low self-acceptance $(\mathrm{t}=4.8 ; \mathrm{p}=0.00)$. The patients with negative self-image (compared to those with positive self-image) deem also their quality of life to be poor $(t=3.1 ; p=0.00)$. Conclusion: A relationship has been found to exist both between mental health condition and the subjective assessment of life quality, and self-image. Thus, both patient's mental health status and his/ her self image constitute major determinants of the quality of life that are worth to be monitored in dermatology patients. Their treatment procedure should include also psychological consulting or psychotherapy.
\end{abstract}

Key words:

Quality of life, Self image, Skin diseases, Mental disorders

\section{INTRODUCTION}

Self-image constitutes an essential element of the personality structure that affects human mental life and attitude to the external world. Self-image controls human activities, relationships with the environment, behaviours particularly in difficult circumstances $(1,2)$. Self-image is made of a person's assumptions and notions about himself/herself — about his/her apperance, abilities and skills, attitudes towards other people, and also about the way in which he/she perceives (2-4) his/her environment. Selfimage is a predictor of the general life satisfaction (5) and thus affects the assessment of the quality of life.
Quality of life (QOL) is a multidimensional concept that is difficult to define and measure (6-9). Our approach is based on Gill's and Feinstein's definition of quality of life. They defined the quality of life as a way (attitude, reflection) in which a patient senses and reacts to his/her health condition and to other, non-medical aspects of his/her life (6). According to this viewpoint, quality of life comprises factors, such as physical, functional, emotional and intellectual well-being, work, family, friends and other particulars. In spite of numerous concepts and definitions of quality of life, the majority of the researchers agree that factors affecting quality of life should be divided into two

Received: July 7, 2008. Accepted: October 29, 2008.

Address reprint requests to A. Potocka, Department of Work Psychology, Nofer Institute of Occupational Medicine, ul. Teresy 8, 91-348 Łódź, Poland (e-mail: garczar@imp.lodz.pl). 
groups: objective and subjective (9-11). The subjective factors (person's subjective opinion) include self-assessment of physical condition (e.g.: general efficiency and fitness, ailments); mental condition (anxiety, depression, self-esteem, self-image); social situation (e.g.: satisfaction with job, earnings, leisure time); interpersonal relations (e.g.: social support, interactions with other people). The term 'objective components of quality of life' refers to medical/psychological diagnosis, results of laboratory testing, indicators of socio-economic status (e.g. net income per capita in the family).

As stated above, condition of health, both physical and mental, is an essential predictor in the assessment of the quality of life. On the other hand, self-image is one of the factors that may affect well-being. The self-image may be favourable and give rise to favourable emotions or unfavourable, giving rise to anxiety, fear and various symptoms of misadaptation. Thus, self-image, by affecting mental health, indirectly influences also our quality of life. Selfassurance, sense of one's own worth and self-acceptance constitute a source of our confidence in our vitality and of our conviction about our self-reliance (12). If a person starts to think that due to illness he/she became worthless and worse than other people, he/she will develop a negative self-image. On the other hand, the sense of inferiority releases adverse emotions (such as e.g. anger and depression) and, as already stated, mental condition is a major factor in the assessment of the quality of life. It is worth stressing here that self-image may be of paramount importance in the diseases that evidently change patient's looks. Dermal diseases evidently fall into that category. Most authors agree that a dermal disease, which changes the appearance of patient's skin, causes that patient reacts by abashment, anger, anxiety, depression (13-15). Thus, dermal diseases considerably affect patient's mental condition, self-acceptance, social function and adaptation (16-23). Reduced self-acceptance, low self-esteem, negative body image and low sense of self-efficacy were noted in patients with visible dermal disorders $(13,15,24,25)$. Unpleasant physical ailments (e.g. burning, itching or painful skin), and the necessary application of various agents (e.g. ointments) result in numerous changes in patient's everyday life (impede or completely prevent normal functions), which results in a considerable mental discomfort $(14,26)$. Thus, in most cases, assessment of the quality of life among the dermatology patients is low $(16,17,19$ 22,26). A person affected by dermal problems must, in the first place, cope with his/her own emotional reactions and, in the second place, with restraints in the person's everyday (professional, family, social) life. Progression of each disease detrimentally affecting the quality of life takes place not only on the biological, but also on the mental level. Patients at low mental condition or with low selfacceptance lose during the treatment the advantage of the full mobilisation of their defensive power (12). Thus, in our opinion, both patient's mental condition and his/her self image constitute major determinants of the quality of life that are worth to be monitored not only in dermatology patients but also in other patients.

Based on literature review, we developed a conceptual framework for the effects of skin disease on patient's quality of life (Fig. 1).

The model illustrates complexity of relationship between dermal disease and quality of life. Discussing the all assumptions that could be drawn from the model is out of the scope of this paper. What we wish to underline here is that the model, apart from classical factors affecting quality of life, includes also self-image dimension. Self-image, as it is presented in Figure 1, may affect quality of life directly or indirectly. The aim of research was to analyse potential relations between self-image, mental health and quality of life.

Taking into account cross-sectional character of the study and size of the sample, the results presented below cannot be generalized and discussed in cause-effect terms. However, we believe that preliminary conclusions drawn

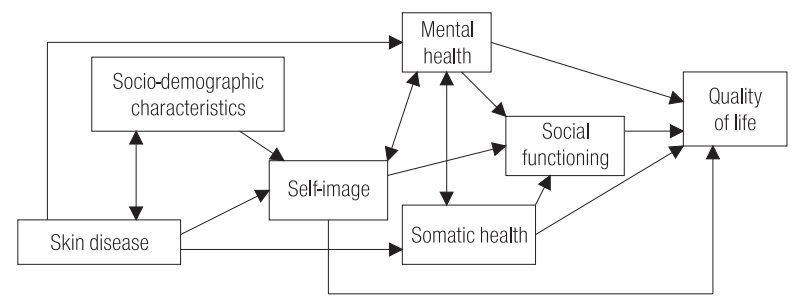

Fig. 1. Conceptual framework for the effects of skin disease on patient's quality of life. 
from the study will focus attention both of researches and practitioners to the role of self-acceptance as the potential determinant of mental health and quality of life among dermatology patients and stimulate deeper exploration of the problem.

\section{MATERIALS AND METHODS}

The group under study comprised patients of the Occupational Disease Outpatient Clinic and Occupational and Environmental Allergy Centre, Nofer Institute of Occupational Medicine (NIOM), Łódź., Poland, and the work was performed in the period since January 2005 till December 2006. The following criteria were applied in the enlistment of the participants:

- women and men not younger than 18 ;

- people with one of the following allergic skin diseases: urticaria, atopic dermatitis, allergic contact dermatitis.

In total, 112 patients were examined, including 37 with diagnosed urticaria, 50 with allergic contact dermatitis and 25 with atopic dermatitis. The subjects included 75 women and 37 men, at the age ranging from 18 to 72 years. The mean age of the study group was 38 years. Individuals

Table 1. Characteristics of the study group

\begin{tabular}{lcccc}
\hline Characteristics & $\begin{array}{c}\text { Total } \\
\mathrm{N}=112\end{array}$ & $\begin{array}{c}\text { Urticaria } \\
\mathrm{n}=37\end{array}$ & $\begin{array}{c}\text { Allergic } \\
\text { contact } \\
\text { dermatitis } \\
\mathrm{n}=50\end{array}$ & $\begin{array}{c}\text { Atopic } \\
\text { dermatitis } \\
\mathrm{n}=25\end{array}$ \\
\hline Sex (n) & & & & \\
Women & 75 & 29 & 28 & 7 \\
Men & 37 & 8 & 22 & 18 \\
Age (years) & & & & \\
Mean & 38.32 & 40.89 & 39.92 & 31.32 \\
SD & 13.15 & 13.45 & 12.12 & 12.54 \\
Training (\%) & & & & \\
Primary & 10 & 11 & 8 & 12 \\
Vocational & 26 & 19 & 30 & 28 \\
Secondary & 44 & 46 & 48 & 32 \\
B. Sc.(BA) & 5 & 5 & 4 & 8 \\
M. Sc.(MA) & 15 & 19 & 10 & 20 \\
\hline
\end{tabular}

SD — standard deviation. with secondary and vocational-type training dominated in the study group. Table 1 gives the basic characteristics of the group.

General Health Questionnaire (GHQ), a 28 item scaled version, was used to diagnose subjects' mental health. This self-administered screening instrument is designed to detect current diagnosable changes in the mental health status and to identify cases of potential mental disorders, leaving a detailed diagnosis to a psychiatric interview. The validation studies of the Polish version of GHQ-28 showed that the internal consistency coefficients (Cronbach's alpha) reached the value of 0.934 . Test-retest reliability ( $\mathrm{r}$ approximately 0.7 ) seems to be good enough. The response options were scored $0,1,2$ and 3 . The total possible score on the GHQ 28 ranges from 0 to 84 and allows for means and distributions to be calculated, both for the total, as well as for the four sub-scales (somantic symptom, anxiety and insomnia, social dysfunction and severe depression). A higher score would indicate poorer psychological health (27).

Quality of life was assessed by calculating an index showing how dermal symptoms affect patient's everyday functions by means of Dermatology Life Quality Index (DLQI). Reliability for the Polish version is satisfactory (correlation coefficient $=0.56$ ) and internal consistency is good (Cronbach's alpha $=0.90)$. All items may be summed to form a total score indicating the overall degree of quality of life, with higher scores indicating greater impairment of quality of life. Items may be aggregated into the following six categories: symptoms and feelings, daily activities, leisure, work and school, personal relationships and treatment, thus forming six separate scores (28).

As we could not find in the Polish literature any method for assessment of self-image suitable for use in our present work, we developed Self-Acceptance Scale (SAS). The Questionnaire comprises 12 items referring to the level of self-acceptance, the feeling of self-effectiveness and self-knowledge. Theoretical foundations underlying its construction were Reykowski's regulatory theory of personality and Argyle's viewpoint $(1,2)$. According to those approaches, self-image consists of a person's assumptions and notions about appearance, abilities and skills, attitudes 
towards other people. Self-image controls human activities, behaviours and relationships with the environment (1-4).

There were two sources of questionnaire items:

- existing tools designed for assessment of different aspects of personality, e.g.: The Minnesota Multiphasic Personality Inventory (29); Gough Adjective Check List (30);

- experts. The preliminary version of the SAS consisted of 25 items.

After statistical analysis, 12 items were included to the final SAS version. Each item includes response scale in a Likert format (from 1 = 'I do not agree definitely' to 5 = 'I definitely agree'). A higher score would indicate more positive self image. The psychometric characteristics of the questionnaire are considered to be satisfactory. A preliminary 14 days test-retest comparison of total scores made on sample of 100 volunteers showed satisfactory reliability (correlation coefficient $=0.72$ ). Internal consistency of the scale is good (Cronbach's alpha $=0.85$ ).

\section{RESULTS}

The obtained data were analysed with the help of the STATISTICA software. Distributions of analysed variables were approximated to a normal. During the first stage of the analysis, Pearson's correlation coefficients (r) were

Table 2. Pearson's correlation coefficients ( $r$ ) between the condition of mental health and assessment of the quality of life and the level of self-acceptance

\begin{tabular}{lc}
\hline \multicolumn{1}{c}{ Mental health (GHQ) } & Self-acceptance (SAS) \\
\cline { 2 - 2 } & $\mathrm{r}$ \\
\hline Sub-scales & \\
Somatic symptoms & -0.29 \\
Anxiety and insomnia & -0.50 \\
Social dysfunction & -0.40 \\
Severe Depression & -0.56 \\
Total score & -0.52 \\
Quality of life (DLQ) & -0.33 \\
\hline
\end{tabular}

$\mathrm{p}<0.05$.

GHQ - General Health Questionnaire; SAS - Self-acceptance Scale; DLQ - Dermatology Life Quality Index. calculated for the relationship between the condition of mental health, and the subjective assessment of the quality of life and the level of self-acceptance. Table 2 gives the results.

The correlation coefficients presented above point to a connection both between the condition of mental health and subjective assessment of the quality of life and the self-acceptance. The lower the self-acceptance of a person, the poorer is his/her condition of mental health. The weakest association was found to occur between the level of self-acceptance and the somatic symptoms. This means that self-acceptance is not associated with the somatic symptoms in a person. The correlation coefficients quoted above point to a relationship between self-acceptance and the subjective assessment of the quality of life. The quality of life is assessed higher among individuals whose selfacceptance is higher.

An additional test was performed to asses the relationship between self-assumptions and GHQ subscales and self-assessment of the quality of life (items of the DLQI questionnaire). We wished to know which of the assumptions about oneself are most strongly correlated with the symptoms of disturbed mental health and the assessment of the quality of life. Tables 3 and 4 give the results.

Analysis of the results above points to the strongest correlations between self-assumptions and the symptoms of depression (subscale D). This means that a person who thinks himself/herself to be attractive and content with his/ her masculinity/femininity, self-assured and able to enjoy life is psychologically healthier. The correlation coefficients obtained in this study show that the weakest correlations occur between self-acceptance and the frequency and intensity of the somatic symptoms diagnosed by the GHQ questionnaire.

Considering the coefficient of correlation between the items of SAS and DQLI, it has been found that most of statistically significant associations occur between $2^{\text {nd }}, 5^{\text {th }}$ and $9^{\text {th }}$ self-assumption and the individual items of the DQLI questionnaire. The associations are not considerable but are evident. The more a person feels depressed and the more he/she is dissatisfied with himself/herself 
Table 3. Correlation coefficients for the relationship between individual ideas about self-image and the symptoms of disturbed mental health status

\begin{tabular}{|c|c|c|c|c|}
\hline \multirow{3}{*}{ Self-Acceptance Scale items } & \multicolumn{4}{|c|}{ General Health Questionnaire subscales scores } \\
\hline & Somatic symptoms & $\begin{array}{l}\text { Anxiety and } \\
\text { insomnia }\end{array}$ & Social dysfunction & Severe depression \\
\hline & \multicolumn{4}{|c|}{$\mathrm{r}$} \\
\hline I like myself & n.s & n.s & n.s & $-0.22 *$ \\
\hline In general I'm depressed & $-0.37^{* *}$ & $-0.48^{* *}$ & $-0.24 * *$ & $-0.34^{* *}$ \\
\hline I am able to enjoy my life & n.s & $-0.25^{* *}$ & $-0.22 * *$ & $-0.44^{* *}$ \\
\hline I am an attractive person & n.s & n.s & n.s & $-0.30^{* *}$ \\
\hline I am not self-satisfied & $-0.31^{* *}$ & $-0.37^{* *}$ & $-0.35^{* *}$ & $-0.43^{* *}$ \\
\hline I am able to achieve a lot & $-0.24^{* *}$ & $-0.43^{* *}$ & $-0.44^{* *}$ & $-0.37^{* *}$ \\
\hline I look worse than other people & $-0.27 * *$ & $-0.36^{* *}$ & $-0.33^{* *}$ & $-0.32 * *$ \\
\hline I am self-assured & n.s & n.s & $-0.22^{*}$ & $-0.30 * *$ \\
\hline Usually I feel strain (tense) & $-0.28 * *$ & $-0.47^{* *}$ & n.s & $-0.35^{* *}$ \\
\hline I feel that I'm a real man/woman & n.s & n.s & n.s & $-0.26^{* *}$ \\
\hline My body is attractive & n.s & $-0.21^{*}$ & n.s & n.s \\
\hline I am satisfied with my choice & n.s & n.s & n.s & n.s \\
\hline $\begin{array}{l}\mathrm{r}-\text { linear correlation coefficient. } \\
\mathrm{p}-\text { level of significance. } \\
* \mathrm{p}<0.05 . \\
* * \mathrm{p}<0.01 \\
\text { n.s. }- \text { non-significant. }\end{array}$ & & & & \\
\hline
\end{tabular}

Table 4. Coefficients of correlation between self-acceptance and subjective assessment of quality of life

\begin{tabular}{|c|c|c|c|c|c|c|c|c|c|c|}
\hline \multirow{3}{*}{ Self-Acceptance Scale items } & \multicolumn{10}{|c|}{ Dermatology Life Quality Index (DLQI) items } \\
\hline & 1 & 2 & 3 & 4 & 5 & 6 & 7 & 8 & 9 & 10 \\
\hline & \multicolumn{10}{|c|}{$\mathrm{r}$} \\
\hline 1) I like myself & n.s. & n.s. & n.s. & n.s. & n.s. & n.s. & n.s. & n.s. & n.s. & n.s. \\
\hline 2) In general I'm depressed & $-0.20^{*}$ & $-0.36^{* *}$ & $-0.33^{* *}$ & $-0.26^{* *}$ & $-0.28 * *$ & n.s. & $-0.35^{* *}$ & $-0.43^{* *}$ & n.s. & $-0.28^{* *}$ \\
\hline 3) I am able to enjoy my life & n.s. & n.s. & n.s. & n.s. & n.s. & n.s. & $-0.24^{*}$ & n.s. & n.s. & n.s. \\
\hline 4) I am an attractive person & n.s. & n.s. & n.s. & n.s. & n.s. & n.s. & n.s. & n.s. & n.s. & n.s. \\
\hline 5) I am not self-satisfied & n.s. & $-0.34^{* *}$ & $-0.31^{* *}$ & $-0.21 *$ & $-0.22 *$ & n.s. & $-0.33^{* *}$ & $-0.37^{* *}$ & n.s. & $-0.33^{* *}$ \\
\hline 6) I am able to achieve a lot & n.s. & n.s. & n.s. & n.s. & n.s. & n.s. & n.s. & n.s. & n.s. & $-0.20 *$ \\
\hline 7) I look worse than other people & n.s. & n.s. & n.s. & n.s. & n.s. & n.s. & $-0.31^{* *}$ & $-0.27^{* *}$ & n.s. & $-0.22 *$ \\
\hline 8) I am self-assured & n.s. & n.s. & $-0.25^{* *}$ & n.s. & n.s. & n.s. & n.s. & n.s. & n.s. & n.s. \\
\hline 9) Usually I feel strain (tense) & $-0.25^{* *}$ & $-0.23^{* *}$ & $-0.21^{*}$ & n.s. & n.s. & n.s. & $-0.30 * *$ & $-0.22^{*}$ & n.s. & n.s. \\
\hline 10) I feel that I'm a real man/woman & n.s. & n.s. & n.s. & n.s. & n.s. & n.s. & n.s. & n.s. & n.s. & n.s. \\
\hline 11) My body is attractive & n.s. & n.s. & n.s. & n.s. & n.s. & n.s. & n.s. & n.s. & n.s. & n.s. \\
\hline 12) I am satisfied with my choice & n.s. & n.s. & n.s. & n.s. & n.s. & n.s. & n.s. & n.s. & n.s. & n.s. \\
\hline
\end{tabular}

Abbreviations as in Table 3. 
Table 5. Differences in mental health condition and subjective quality of life in relation to self-image

\begin{tabular}{lrrrcc}
\hline \multirow{2}{*}{ Variable } & \multicolumn{5}{c}{ Self-image } \\
\cline { 2 - 6 } & & High & Low & Test-t & $\mathrm{p}$ \\
\hline Mental health & $\mathrm{M}$ & 29.3 & 18.7 & 4.8 & 0.00 \\
condition & $\mathrm{SD}$ & 12.3 & 8.3 & & \\
Subjective & $\mathrm{M}$ & 8.8 & 12.9 & 3.1 & 0.00 \\
quality of life & $\mathrm{SD}$ & 6.7 & 6.5 & & \\
\hline
\end{tabular}

and his/her looks, the stronger he/she senses the impact of the disease on his/her everyday life.

The next step of our analysis was to find out whether self-image affected mental health condition or the subjective quality of life of the patients. The patients were divided into two groups, one with more positive and the other with a poorer self-image. More positive self-image patients are those who obtained high SAS scores, while poorer self-image patients are those with low SAS scores. Low SAS scores are those which are lower than, or equal to the median value, while high SAS scores are those above the median value for the test group (Table 5).

The analysis of the results shows that there were statistically significant differences in the assessment of mental health and quality of life, depending on the level of

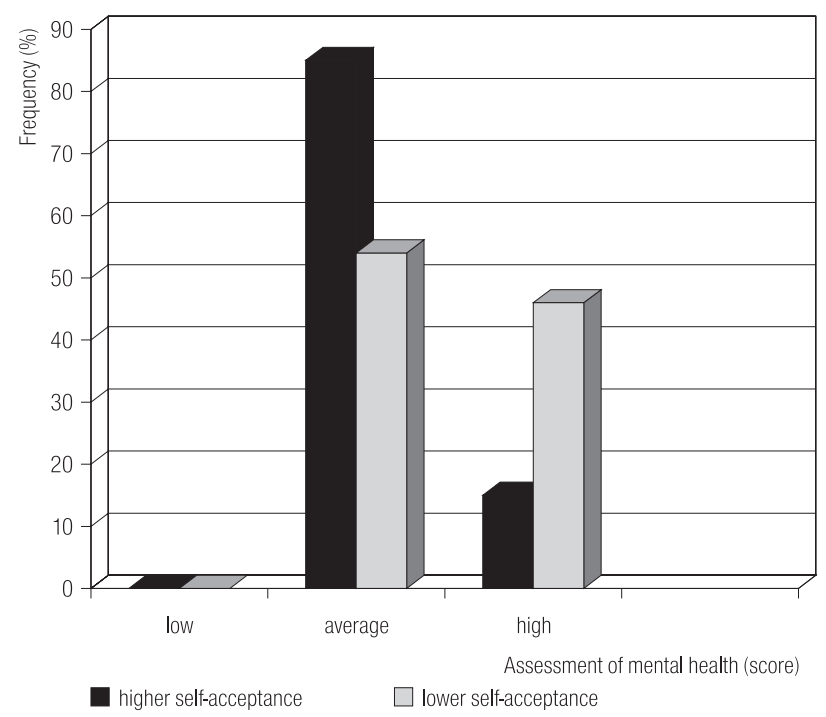

Fig. 2. Distribution of results of mental health assessment in two groups: with higher and with lower self-acceptance.



Fig. 3. Distribution of the results of subjective assessment of the quality of life in two groups: with higher and with lower self-acceptance.

self-acceptance. Individuals with high self-acceptance are characterised by better mental health condition than those with low self-acceptance. The self-image affects also person's assessment of quality of life. The patients with poorer self-acceptance (compared to those with positive self-acceptance) deem also their quality of life to be poor.

We decided to check in the course of the analysis what GHQ and DLQI results were in two groups of patients (with higher and those with lower self-acceptance). One of our aims was to find out what proportion of non-self-accepting patients experienced mental health disturbances and how many of them reported unsatisfactory quality of their life. Figures 2 and 3 show the distribution of the results.

From the graph above one may conclude that as much as 46 per cent of patients with lower level of self-acceptance suffer some mental health problems. At the same time, mental health problems were detected in only $15 \%$ of subjects with higher level of self-acceptance.

When analysing the distribution of the results of the assessment of quality of life by patients with higher and lower level of self-acceptance one may conclude that as much as $67.5 \%$ of the high self-acceptance individuals assess the quality of their lives as high, whereas only 43 low self-acceptance patients assess it in the same way. 


\section{DISCUSSION}

Most authors agree that chronic skin diseases bring many changes to patients' everyday life, causing a considerable mental discomfort (13-16,18-20). However, in the accessible literature, we could not locate any data indicating directly that self-image could play a significant (or an insignificant) role, for example in assessing quality of life or in the assessment of mental health. Standardised tools that would enable comprehensive researching such complex construct as self-image are not available either. Therefore, it was not possible to compare our results with literature data. The lack of data on the role of self-image in the treatment of dermatology patients and a few reports on mental health and quality of life of those patients have induced us to start the research resulting in findings presented in this paper. Professionals working on a daily basis with dermatology patients are able to note, during simple observation, that a considerable number of those patients are characterised by low self-acceptance, low self-esteem, negative body image or low sense of self-efficacy. The conclusions from those observations are not surprising, because visible dermal changes are known to adversely affect human mental condition and result in depression, anxiety and pessimistic attitudes (31-33). It is worth noting here that the frequency of mental disorders among dermatology patients is higher than in the general population; it is as high as ca. 30\% (32,34-37). This is confirmed by numerous studies; for example Fritzsche (38), after he had examined 86 dermatology patients, in as much as $46 \%$ of them diagnosed mental (affective and anxiety-related) and behavioural disorders. According to the results obtained by Hughes et al. (35), 30\% outpatient clinic patients and 60\% hospital patients with dermal problems are affected by mental disorders. Wesseley and Lewis (37) confirm the prevalence of mental disorders in $40 \%$, while Aktan et al. in $33.4 \%$ of the examined patients (including $12 \%$ suffering from anxiety and $10 \%$ suffering depression). As dermal diseases are often associated with remarkable changes of patient's appearance, they may cause that the patients develop a negative image of his/her body $(15,21,25)$. The negative image of one's own body and the accompanying powerful stress magnifies the sense of anxiety and helplessness, which may lead even to suicidal attempts $(21,37)$. Gupta and Gupta (36) report that suicidal tendencies were detected in $7.2 \%$ hospitalised patients with psoriasis and in 5.6\% patients with acne. In another study the same authors showed that dermal changes which were extensive or located in places critical for patient's self image (face, hands) might significantly contribute to the development of depressive symptoms. Chronic dermal diseases remarkably change patients daily routines, because, by way of example, of the necessity to adhere to doctor's recommendations $(23,25)$. The limitations in patient's private life result not only from the onerous and hard-to-treat dermal changes but also from the applied therapy. It is often the case that executing normal tasks, such as shopping, cleaning or baby care are practically impossible, e.g. for patients with dermal changes located on their hands (26). It is quite reasonable to expect that a patient encumbered with such limitations may perceive himself/herself as useless and worthless. A perception like that may result in a negative self-image.

The data quoted above may indicate indirectly that selfacceptance level may play a major role in the progression of the disease and recovery of patients with dermal problems. Results of studies on patients with diseases other than dermal also indicate that it is worthwhile to pay more attention to the structure of personality, such asself-image. For example, studies on patients with a stable form of angina pectoris revealed significant differences between their current and pre-disease self-image (39). Like in dermatology patients, low self-image, anxiety or reduced taskachieving persistence were noted in that group of subjects. Swedish authors studied occupational burnout in whitecollar workers of psychiatric hospitals (40). They examined 754 employees and found that negative self-image adversely affected their ability to cope with occupational problems and, therefore, might constitute a risk factor of professional burnout.

Considering that only few reports are accessible on selfimage and its relationship with the condition of mental health and the level of the quality of life, and considering the examples quoted above, we had been convinced that the problem should be analysed more extensively. 


\section{CONCLUSION}

This paper reports the results of a cross-sectional study of self-image and life quality in relatively small sample ( $\mathrm{N}=112$ ), so it has exploratory character. The aim of this study was to assess mental health condition and quality of life of dermatology patients with regard to the level of selfacceptance. The results show that there is a relationship between mental health condition, subjective assessment of the quality of life, and self-acceptance. In individuals whose self-acceptance is higher, the risk of mental health disorders is lower than in those, whose self-acceptance is lower. Self-image correlates also with the assessment of quality of life. Patients whose self-acceptance is lower tend to assess their quality of their lives as poorer in comparison to those who appreciate themselves. Taking into account the role of mental health as the potential determinant of quality of life among dermatology patients, their treatment procedure should also focus on counselling. The treatment, in our opinion, should be conducted so as to improve the quality of functioning in that group of patients.

\section{REFERENCES}

1. Tomaszewski T. The psychology. Warszawa: PWN; 1998 [in Polish].

2. Argyle M. The psychology of interpersonal behaviour. Warszawa: PWN; 1999 [in Polish].

3. Pilecka W. Chronic somatic illness in life and development of the child. Kraków: Wydawnictwo UJ; 2002 [in Polish].

4. Żebrowska M. Developmental Psychology of Children and Adolescents. Warszawa: PWN; 1987 [in Polish].

5. Schimmack U, Radhakrishnan P, Oishi S, Dzokoto V, Ahadi S. Culture, personality, and subjective well-being: integrating process models of life satisfaction. J Pers Soc Psychol 2002;82(4):582-93.

6. Kowalczuk-Zieleniec E, Nowicki R, Majkowicz M. Quality of life in dermatology. Methods to measure quality of life. Przegl Dermatol 1999;86:153-8 [in Polish].

7. Sokolnicka H, Mikuła W. Medicine versus quality of life. Med Rodz 2003;24:3-4 [in Polish].
8. Jaeschke R, Guyatt G, Cook D, Miller J. Definition and measuring of health related quality of life. Med Prakt 1999;4:155-62 [in Polish].

9. Żelazny I, Nowicki R, Majkowicz M, Samet A. Quality of life in skin diseases. Przew Lek 2004;9:60-5 [in Polish].

10. O'Connor R. Measuring quality of life in health. Edinburgh: Elsevier; 2004.

11. Jarema M. Research on the quality of life. In: Skłodowski H, editor. Psychosomatic medicine and psychology of patients with psychosomatic diseases in accordance with threat and challenges of civilization modern world. Łódź: Wydawnictwo UŁ; 1996. p. $300-3$ [in Polish].

12. Sarwa A, Polak K, Sarna D. The influence of the patient's selfimage on aetiopathogenesis of the disease. In: Skłodowski $\mathrm{H}$, editor. Psychosomatic medicine and psychology of patients with psychosomatic diseases in accordance with threat and challenges of civilization modern world. Łódź: Wydawnictwo UŁ; 1996.p. 143-6 [in Polish].

13. Koo J, Lebwohl A. Psychodermatology: The mind and skin connection. Am Fam Physician 2001;64(1):1873-9.

14. Steuden S, Jankowski K. The application of the quality-oflife questionnaire SKINDEX in patients with psoriasis. Przegl Dermatol 2001;88:41-8 [in Polish].

15. Papadopoulos L, Walker C, Aitken D, Bor R. The relationship between body location and psychological morbidity in individuals with acne vulgaris. Psychol Health Med 2000;5(4):431-8.

16. Finlay AY, Khan GK. Dermatology Life Quality Index (DLQI) - a simple practical measure for routine clinical use. Clin Exp Dermatol 1994;19(3):210-6.

17. Holness DH. Results of quality of life questionnaire in a patch test clinic population. Contact Dermatitis 2001;44(2):80-4.

18. Smith JA. The impact of skin disease on quality of life of adolescents. Adolesc Med. 2001;12(2):343-53.

19. De Korte J, Mombers FMC, Sprangers MAG, Bos JD. The suitability of quality of life questionnaires for psoriasis research: A systematic literature review. Archives of Dermatology 2002;138:1221-7.

20. Herd RM, Tidman MJ, Ruta DA, Hunter JA. Measurement of quality of life in atopic dermatitis: correlation and validation of two different methods. Brit J Dermatol 1997;136(4): 502-7. 
21. Zalewska A, Miniszewska J, Woźniacka A, Juczyński Z, Sysa-Jędrzejowska A. Coping with illness and quality of life of psoriatic patients. A pilot study. Przegl Dermatol 2003;90:267-72 [in Polish].

22. Chren MM, Lasek RJ, Quinn LM, Mostow EN, Zyzanski SJ. Skindex, a quality of life measure for patients with skin diseases: Reliability, validity and responsiveness. J Invest Dermatol 1996;107(5):707-13.

23. Miniszewska J, Chodkiewicz J, Zalewska A. Psychodermatology - new challenge for psychology. Nowiny Psychol 2004;3:21-31. [in Polish]

24. Borzęcki A, Cielica W. Psychological aspects in psoriasis. Nowa Med 2002;116:40-2 [in Polish].

25. Papadopoulos L, Bor R, Legg C. Psychological factors in cutaneous disease: an overview of research. Psychol Health Med 1999;4(2):107-27.

26. Kadyk DL, McCarter K, Achen F, Belsito DV. Quality of life in patients with allergic contact dermatitis. J Am Acad Dermatol 2003;49(6):1037-48.

27. Goldberg D, Williams P, Makowska Z, Merecz D. Mental Health Assessment on a Research. Basis by David Goldberg Questionnaires. Łódź: IMP; 2001. [in Polish]

28. Szepietowski J, Salomon J, Finlay AY, Klepacki A, Chodynicka B, Marionneau Ne, et al. Dermatology Life Quality Index (DLQI): Polish version. Dermatol Klin 2004;6(2):63-70 [in Polish].

29. Butcher JN, Dahlstrom WG, Graham JR, Tellegen A, Kaemme, B. The Minnesota Multiphasic Personality Inventory-2 (MMPI-2): Manual for administration and scoring. Minneapolis: University of Minnesota Press; 1989
30. Gough HG, Heilbrun AB. The Adjective Check List manual. Palo Alto, CA: Consulting Psychologists Press; 1983.

31. Spiła B, Jazienicka I, Pucuła J. Analysis of psychological factors in patients with skin diseases. Dermatol Klin 2004;6(3):137-41 [in Polish].

32. Gupta MA, Gupta AK, Ellis ChN, Koblenzer CS. Psychiatric evaluation of the dermatology patient. Dermatol Clin 2005;23(4):591-9.

33. Gupta MA, Gupta AK. Depression and suicidal ideation in dermatology patients with acne, alopecia areata, atopic dermatitis and psoriasis. Br J Dermatol 1998;139(5):846-50.

34. Kułak W, Krajewska-Kułak E, Niczyporuk W, Sobaniec W, Sobaniec H. Influence of the central nervous system on the development of skin disorders. Przegl Dermatol 1999;86(4), 407-15 [in Polish].

35. Hughes JE, Barraclough BM, Hamblin LG, White JE. Psychiatric symptoms in dermatology patients. Br J Psychiatry 1983;143:51-4.

36. Fried RG, Gupta MA, Gupta AK. Depression and skin disease. Dermatol Clin 2005;23(4):657-64.

37. Steuden S, Janowski K. Dermatological diseases and psychological disorders. Przegl Dermatol 2000;87:257-61 [in Polish].

38. Gieler U. Psyche and Skin: What's new? J Eur Acad Dermatol Venereol 2003;17(2):128-30.

39. Pawłowska B, Opolska A, Papuć E, Witczak W. Present and premorbid self-image in patients with coronary heart disease. Psychiatr Pol 2006;40(2):1069-79 [in Polish].

40. Jeanneau M, Armelius K. Self-image and burnout in psychiatric staff. J Psychiatr Ment Health Nurs 2000;7(5): 399-406. 